OSF Preprints; doi:10.31219/osf.io/kquhm (Jan 1, 2021)

\title{
Đầu năm 2021, nhớ lại ngày này cách đây 3 năm
}

\author{
VQH
}

Ngày 1 tháng 1 năm 2021

Thời khắc này đã sang ngày đầu tiên của năm mới 2021.

Chợt nhớ lại ngày này 3 năm trước.

Sáng ngày 1-1-2018, cả gia đình tôi đang nghỉ ở vùng quê Gia Viễn, Ninh Bình, nơi đó có đầm Vân Long thơ mộng.

Vùng đất này cơ bản rất yên tĩnh, xung quanh toàn ruộng lúa, đặc trưng cho đồng bằng Bắc Bộ.

Đầm Vân Long mùa đông rét ngọt. Bao quanh là núi.

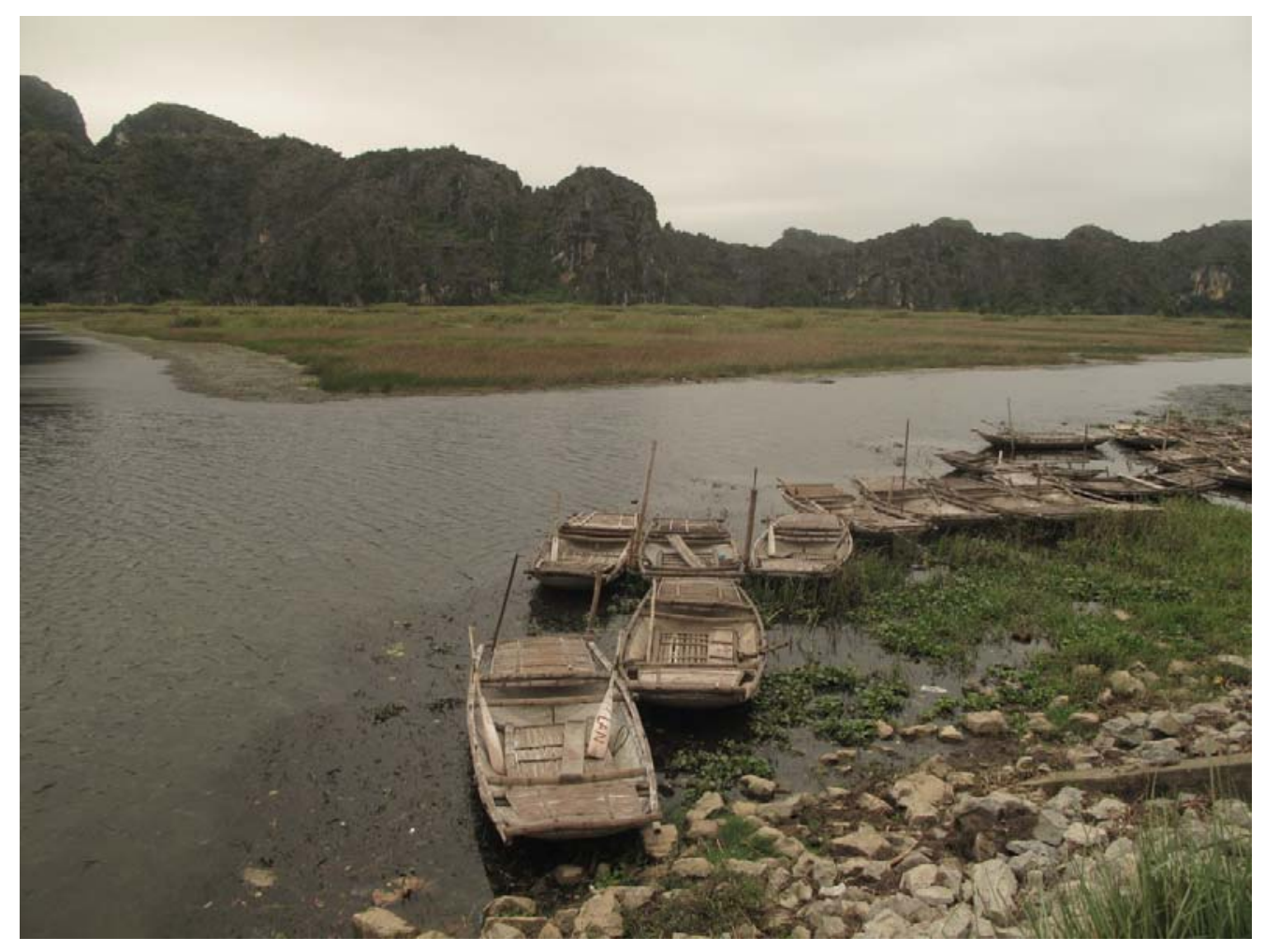

Đò đợi khách bên đầm Vân Long 
Đêm trước ngồi trò chuyện, nghe dế kêu, côn trùng rả rích. Ngẫm ngợi về bài "Thức Khuya" của thi sĩ tài hoa bạc mệnh Hàn Mặc Tử, ${ }^{1}$ trong đó có đoạn:

\section{Khóc giùm thân thế, hoa rợ lệ}

Buồn giúp công danh, dế dạo đàn

Rồi tất cả chìm vào giấc ngủ của ngày cuối cùng năm cũ.

Trên đời này, nếu có ước muốn, thì thú vị nhất là được ước vào ngày đầu năm mới. Mong sao mọi thứ tươi mới, suôn sẻ.

Tuy vậy, không hẳn ước muốn nào cũng “mới toanh”!

Trong công việc nghiên cứu, có nhiều công đoạn kéo dài, và chờ đợi rất mất thời gian.

Làm việc đã vất vả, nhưng chờ đợi lại có kiểu khắc khoải của nó. Đôi lúc tưởng như đã gần xong, nhưng rồi lại chờ đợi. Những thứ cảm thấy có thể dự báo được kết quả, nhưng chưa thấy kết quả thì vẫn là chưa xong. Lại có một thứ nữa, đó là khi một nghiên cứu đã được chấp thuận công bố, thậm chí đã nhận cả bản in thử sản xuất và sửa trả lại (tức là galley proofs), nhưng vẫn phải chờ. Đó là chờ ngày bài báo thực sự xuất hiện trên mặt tạp chí khoa học với bản in chuẩn cuối cùng. Ngày chào đời của đứa con tinh thần. Những ngày ấy càng đến gần thì càng ngóng trông.

Vào ngày 31-12-2017, bản thân tôi cũng ngóng trông như thế. Cho tới lúc cuối ngày, thì cũng chỉ tự nhủ: Việc này rồi sẽ hoàn tất trong năm mới (tức là 2018). Phải nói điều tự nhủ ây là rất "rộng dài" về thời gian. Mỗi năm có tới 365 ngày. Nào ai biết cái việc nghĩ rằng sắp xong đó rồi sẽ thật sự xong vào ngày nào trong số 365 ấy, nhất là khi rất nhiều công đoạn việc không thể chủ động thời gian, chẳng hạn như việc đưa bài lên mặt tạp chí, theo lịch trình của ban biên tập nào đó.

Ngủ rất khuya, và dậy cũng rất muộn... Chừng 10 giờ sáng, bật máy tính và thấy có nhiều email. Trong đó có một email báo vào sáng 1-1-2018: một bài đã xong rất lâu trước đó, bây giờ xuất bản chính thức. Sáng ngày đầu năm mới thế là sảng khoái. Đó là bài đăng trên tạp chí Iranian Journal of Public Health, tập 47, số 1 . Tạp chí này có hệ số tác động 2018 IF 1.225, tuy không phải cái gì ghê gớm, nhưng là ấn phẩm tốt, phản biện nghiêm ngặt.

Chỉ có một điều là quá trình chờ đợi kéo dài. Thực tế, họ đã đồng ý xuất bản bài từ cuối 2016, nhưng phải chờ tới 13 tháng, thì bài mới ra. Có lúc việc sửa chữa bản thảo xuyên qua mùa hè, cộng với sự chờ đợi khắc khoải, khiến tôi nhớ đến đôi câu thơ trong bài "Vào Hè" của Dương Bá Trạc:

Ai xui con cuốc gọi vào hè

Cái nóng nung người nóng nóng ghê...

\footnotetext{
${ }^{1}$ Trước kỳ nghỉ này, cuối năm 2017, tôi có bài viết vui vui theo đề nghị của GS Ngô Bảo Châu, đóng góp cho số tháng 12 của Tạp chí Pi, Hội Toán học Việt Nam, lúc đó Tổng biên tập là GS Hà Huy Khoái [1].
} 
Rồi mùa hè cũng qua, mùa thu tới. Rồi lại cả mùa đông. Sáng đầu năm đón chào bài mới.

Nói chuyện mới đầu năm, bà xã lý giải: Iran họ không ăn tết dương lịch, vì họ theo đạo Hồi. Vì vậy, chắc việc họ làm vẫn diễn ra bình thường.

Quả là một nhận xét có lý, đáng tin cậy!

(Đây là ấn phẩm của nhà xuất bản thuộc Tehran University of Medical Sciences;

https://iiph.tums.ac.ir/).

Ngày đầu năm ấy, đạp xe trên đê cạnh đầm Vân Long thấy không thấy rét. Thấy khí trời mát mẻ, trong lành. Những đám lá sen, quỳ héo tàn cũng vẫn cuốn hút lạ thường.

Đến tối sau bữa ăn gia đình, tôi lại kiểm tra hộp thư.

Trong số thư gửi đến, lại có một cái thông báo bài đăng. Và đó cũng là thư được đón chờ, nhưng quả thật không nghĩ rơi vào ngày 1-1. Thư từ ban biên tập một tạp chí rất uy tín, hàng đầu thế giới Nature Human Behaviour của nhà xuất bản Nature Publishing Group đã tồn tại xuyên thế kỷ 19, 20 và 21. Tạp chí này vô cùng khó tính, khắt khe. Lẽ tự nhiên, để xuất bản được bài trên họ rất gian nan. Năm 2018 tạp chí có IF là 10.575.

\title{
nature human behaviour
}

Explore our content $\vee \quad J o u r n a l$ information $\vee$

nature $>$ nature human behaviour $>$ world view $>$ article

World View | Published: 01 January 2018

\section{The (ir)rational consideration of the cost of science in transition economies}

\author{
Quan-Hoang Vuong $\square$ \\ Nature Human Behaviour 2, 5(2018) | Cite this article \\ $\mathbf{7 8 5}$ Accesses | $\mathbf{5 7}$ Citations | $\mathbf{3 8}$ Altmetric | Metrics
}

Science makes a substantial contribution to the economy of developing countries such as Vietnam and its costs must be put into perspective, argues Quan-Hoang Vuong.

Bài ra trên Nature Human Behaviour ngày 1-1-2018 cách đây tròn 3 năm 
Ba năm sau, lại vào lúc đầu năm, ngẫm ngợi tôi chợt tự hỏi: Nếu không có hai bài này ra vào đầu năm 2018, thì có gì thay đổi với cuộc đời không?

Có lẽ là không có gì thay đổi đáng kể. Tuy nhiên, lại thiếu đi niềm vui khá thú vị. Thực lòng mà nói, đã 3 năm kể từ đó, chưa có ngày đầu năm nào tôi lại nhận được email thông báo như cái ngây này cách đây 3 năm cả.

Thực ra, ngày 1-1-2020 cũng có một việc hay, nhưng sự kiện thực tế lại xảy ra vào ngày 2-1. Đó là "Lễ ký kết thỏa thuận hợp tác giữa Viện Nghiên cứu cao cấp về Toán và Quỹ Đổi mới Sáng tạo Phenikaa." Hôm 1-1, tôi nhận được điện thoại của GS Ngô Bảo Châu, người cùng khởi tạo dự án xây dựng cơ sở dữ liệu nhân vật-tác phẩm cho ngành toán học Việt Nam trải qua gần 80 năm, kể từ tháng 8 năm 2017, về việc chính thức hóa hợp tác thông qua Trường Đại học Phenikaa, nơi tôi đang công tác. Đến 2-1 thì lễ này chính thức diễn ra [4]. Cũng nhờ sự kiện này, nhóm nghiên cứu và dữ liệu SciMath mới có xung lực để thúc đẩy tới việc ra đời bộ cơ sở dữ liệu thử nghiệm vào tháng 11-2020 (tức là mới đây thôi), và có được bản thảo preprint đầu tiên (arXiv:2011.09328) trình bày chi tiết hơn về CSDL SciMath Việt Nam. Tuy vậy, sự kiện đó vẫn là ngày 2-1.

\section{Tham khảo:}

[1] Hoàng VQ. (2017). Mỹ cảm thi ca qua một lăng kính toán học. Tạp chí Pi, 1(12), 5-7. (URL: https://osf.io/gduvw)

[2] Vuong QH. (2018). Sociodemographic factors influencing Vietnamese patient satisfaction with healthcare services and some meaningful empirical thresholds. Iranian Journal of Public Health, 47(1), 119-126.

[3] Vuong QH. (2018). The (ir)rational consideration of the cost of science in transition economies. Nature Human Behaviour, 2(1), 5-5.

[4] VIASM. (2020). Lễ ký kết thỏa thuận hợp tác giữa Viện Nghiên cứu cao cấp về Toán và Quỹ Đổi mới Sáng tạo Phenikaa. Trang tin VIASM (2-1-2020). URL: https://viasm.edu.vn/hoat-dongkhoa-hoc/tin-tuc/chi-tiet/le-ky-ket-viasm-va-phenikaa

[5] Chau NB, Hoang VQ, Phuong LV, Hoa LT, et al. (2020). The 80-year development of Vietnam mathematical research: Preliminary insights from the SciMath database on mathematicians, their works and their networks. arXiv preprint arXiv:2011.09328.

https://arxiv.org/abs/2011.09328 